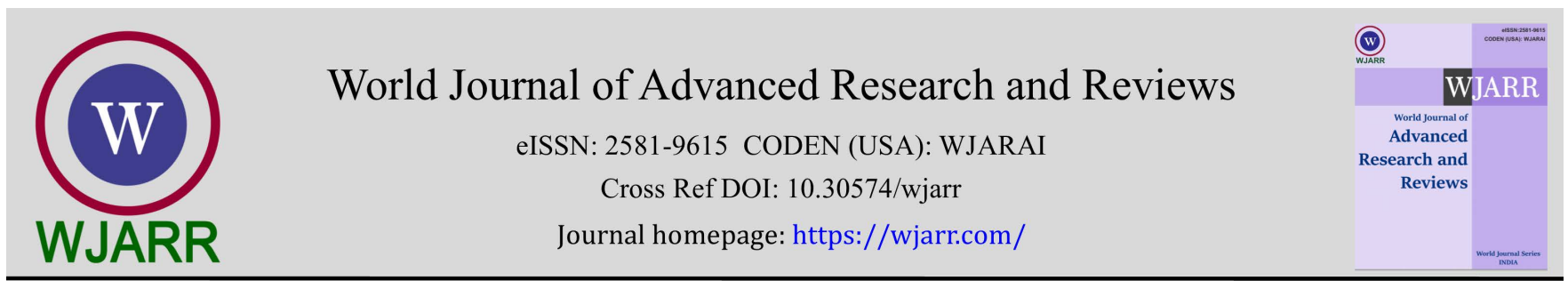

(REVIEW ARTICLE)

Check for updates

\title{
The omnipresent power of the invisible: From viruses to being conscious
}

\author{
Castañeda Cataña MA, Sepúlveda CS and Carlucci MJ * \\ Buenos Aires University-CONICET. Biological Chemistry Exact and Natural Sciences Institute (IQUIBICEN), Virology \\ Laboratory QB19, Buenos Aires, Argentina
}

World Journal of Advanced Research and Reviews, 2021, 12(02), 518-525

Publication history: Received on 15 October 2021; revised on 23 November 2021; accepted on 25 November 2021

Article DOI: https://doi.org/10.30574/wjarr.2021.12.2.0617

\begin{abstract}
According to Mayan cosmology, the law of time is represented as the energy factored by time equals to art. Time is a form of biological information. Time in-forms life, in such a way that life forms processes time as information and externalize it specific forms into the three-dimensional world, then time is the principle ordering of life. Indeed, everything in the natural order of the cosmos is beauty and harmony. All life forms on planet earth have their phases of morphological development, this is real even in the social structure of communities of living beings that also may have an aesthetic or artistic quality. This form and measurements of all things constitutes the entire or holistic order of the universe. So, if life is it nothing more than better-informed matter, where does this information come from? Socrates and Platon held that nothing in nature and in the world can be explained by random or chance, as Democritus would have argued, that nature creations occur because they have a Purpose. According to Platon, the natural world is a designer's result demiurge or a universal consciousness that sets everything in the best possible place. So, if there is a start point where intelligence creates order, where there is order, there is purpose so; what is the purpose then? This work tends to give an answer and show a different perspective of living, studying and understanding (micro)biological phenomena in order to become conscious and assume that Nature is infinitely more powerful than us, the Whole is more than the sum of parts, we are part of it.
\end{abstract}

Keywords: Evolution; Virus; Consciousness; Cosmos; Nature; Genomes

\section{Introduction}

There exists an original pattern for each being in the universe, from which every model that exist is generated. We are all the same; we are all different. According to the Mayans, this is the only source of energy from which the world originates, this energy manifests itself in an infinite number of forms and at various dimensional levels. Each of these forms is a vibration of certain frequencies, the entire material world is fundamentally energy; reality is composed by frequencies, vibrations, harmonies. The cyclical order of time determines life within the three-dimensional material space world. While the order of synchronic time corresponds within the fourth dimension, described as mental, imaginary, which precedes the physical; not only precedes, contains it. As the universe is so vast, it is interesting to see when we lie down at night to appreciate the stars, that the universe fits in our mind, it is contained by our mind. We can watch and feel everything in time through our body. So, the third dimension means the physical, manifestation or projection of the fourth dimension. We haven't created anything within the material world, everything existed before, like a thought in the mental sphere [1]. This is a very simple way of showing that thoughts precede manifestations, mind precedes matter, time precedes and contains space. Based on the above, we propose to recall a different vision of the scientific knowledge to create new possibilities of perceiving more consciousness from the invisible (viruses) to the matter world.

\footnotetext{
${ }^{*}$ Corresponding author: Carlucci MJ

Buenos Aires University-CONICET. Biological Chemistry Exact and Natural Sciences Institute (IQUIBICEN), Virology Laboratory QB19, Buenos Aires, Argentina.
}

Copyright (C) 2021 Author(s) retain the copyright of this article. This article is published under the terms of the Creative Commons Attribution Liscense 4.0. 


\section{Order and Purpose}

The difference between a stone and a cell is that the cell seems infinitely more structured, more ordered than the stone, at molecular level it is much more important than the anatomical one, and they are related to the differences within matter, between the mineral world and the organic world, the decisive leap occurs at macromolecules levels. This example allows us to capture differences only in the background, between the inert and the living. One has a rich information from the other. If life is nothing more than better informed matter, where does this information come from?

According to Ilya Prigogine: disorder is not a NATURAL state of matter, on the contrary, it is a stage that proceeds to the emergence of a higher order [2]. In the first place, it must be verified that things that are around us behave like open systems, that they exchange matter, energy and information in a perpetual way within their environment. What is possible in the dynamics of liquids must be also possible in chemistry and biology. In other words, these perpetual system motions vary regularly over time and must be considered as fluctuating. From here there are two options possible: Either the system is destroyed by amplitude of fluctuations, or the access to a new internal order, characterized by a higher organization level. Extremely disturbed by the omnipresence of this order underlying the apparent matter chaos, Prigogine declared one day: What is surprising is that each molecule knows what the other molecules will do while they are at macroscopic distances. Everyone accepts this property with living systems, but it is at least unexpected with inert systems. In reality, life derives its properties directly from that mysterious matter tendency to organize itself, spontaneously, to move towards ever more orderly and complex states. If there is a constant progress of matter towards more orderly states, if there is an evolution of the species towards superspecies (humanity) then this leads us to think that there is, a cause of harmony of the causes, an intelligence at the bottom of the universe itself. The manifest presence of this intelligence, down to the heart of matter, distances us forever from the conception of that the universe would have appeared "by chance", which have produced life "by chance" and intelligence "by chance". Let's give examples, a living cell is composed about twenty amino acids that forms a compact "chain". The function of these amino acids in turn depends on about 2000 specific enzymes. Following the same reasoning, it is calculated that the probability of a thousand different enzymes to approach in an orderly manner until they form a living cell (in the course of an evolution of several thousand years) is of the order 101000 against 1 [3]. Two numerous teams studied the in patterns interaction between cellular proteins and have found that around $85 \%$ of proteins associate with others to perform their functions, in a number of at least 96 associations. Each combination determines their structures and functions characteristic. This ability to combine surely is the cause of confusion that estimates the number of cellular proteins that, according to the sources, can vary between more than 30,000 and $250,000[4,5]$.

The "relativistic quantum theory of fields" establishes that a particle does not exist by itself but through the effects it generates. This set of effects is called a "field". The objects that surround us are none other than sets of fields (electromagnetic field, gravitational field, proton field, electric field, etc.) that interchange permanently between them. What the relativistic quantum theory of fields describes is not the particles such as objects, but their incessant, innumerable interactions with themselves. We can say now that reality is nothing more than a set of fields, but what is the constitution of those fields? Since elementary particles are generated by fields, their effects exist in the ordinary physical world and are therefore measurable. So, we can say that the fundamental reality is nothing other than a large information matrix [6]. Reality should then appear as an infinite network of interconnections, a limited model of models and plans reserve that intersect and combine according inaccessible laws to us and though we may never understand [7].This is with no doubt at all what the physicist David Bohm refers to, when he affirms that "In the depths of real there is an implicit order hidden" [8]. In this sense, we would have to admit that the entire universe would be full of intelligence and intention: from the smallest elemental particle to the galaxies and what is extraordinary is that in both cases there is the same order and the same intelligence. Which brings us irresistibly to the point of view of Teilhard de Chardin, for whom everything in the universe down to the smallest particle carries a certain degree of consciousness $[2]$.

\section{Towards meta-realism}

Philosophies for which reality "in itself" is not knowable are grouped under the name of idealism: the only evidence of an external world resides in our perceptions, in our sensations of color, dimension, taste, shape, etc. From the moment we are born, we are taught that we have to have a common world perception, what a person perceives as a tree, a flower, a river, any other person must perceive it as, tree, flower, or river. This is the direct consequence of our common beliefs in a given world. The cybernetician Heinz von Foerster states that the human spirit does not perceive what is there, but what it believes is there. Our seeing faculty depends on the retina that absorbs light from the outside world, which then transmits signals to the brain. This same system applies, on the other hand, to all our sensory perceptions. However, the retina does not perceive color, explains von Foerster; it is blind to the stimulation quality and only is sensitive to its 
quantity. This shouldn't come as a surprise, he adds, as there is actually no color in itself - there are only electromagnetic waves. There is neither sound nor music, only momentary variations of the air pressure on our eardrums.

There is neither cold nor hot: only molecules in motion, with more or less kinetic energy and so on. According to idealists, we are not born as part of the world: we are born as part of something we build inside the world. Liberalism imposes the idea that each one of us lives in a kind of a consciousness sphere that interferes at the same time with the real, the unknown, and with other consciousness spheres. Once again, the conception of objective reality evaporates.

Wondering about reality that surrounds us, without taking into account those who observe it, makes no sense [9,10]. Deep down in my own consciousness sphere I will not get any information about reality itself: my knowledge of the world is reduced to the idea that I create of it in terms of reality, beyond my feelings, it remains dark, veiled, mysterious. And probably, according to the expression of Bernard d 'Espagnat, unknowable [11]. Here we reach an idea analogous according to Heisenberg's Uncertainty Principle, we do not observe the physical world: we participate in it. Our senses are not separated from what exists in itself but are intimately involved in a complex process of feedback whose final result is actually to create what is in itself. In a way, the universe dream through us about itself: materialism itself begins when the dreamer dreams and consciousness appears and from its dream $[7,12]$

\section{Relationship between information, organization and entropy of a system}

With most physicists we can admit that the acquisition of information, of knowledge, consumes energy and then causes global growth entropy within a system. In other words, if entropy measures the system physical disorder, it is at the same time an indirect indicator of locally maintained amount of information by that same system. Theory information then leads to this surprising statement: Presence indicates chaos within a system, with certain amount of information.

\subsection{Viruses and evolution}

The experimental studies of Harrison (1937), Weiss (1939) and Child (1941), have arrived at the fundamental concept of "morphogenic field" [13,14,15]. These "fields" are areas of embryological information whose components are networks of interactions, each cell acquires an embryonic potential defined by its position within each field. These complex interactions observed in the embryos were hardly reconcilable with the theoretical mathematical planning of population genetics, the mathematical models took center stage to explain an invisible phenomenon "evolution" that led to ignoring the existence of contradicting processes, that they are clearly observable in the laboratory. Once again, the social component carried more weight than the scientific arguments $[16,17,18]$. At embryonic, morphogenic fields level development with incredible precision, control the spatial and temporal process of tissue and organ formations and are capable of correcting accidents and redirecting the process. At the organic level, control is given by the neuroendocrine regulatory systems that relate tissues and organs to each other, under the protection of a complex immune system with a surprising capacity to respond to foreign agents. The great precision with which each of these mechanisms works and the close interconnection between all of them, their quality of complex systems, whose elements cannot act as independent parts, gives little room for action to random errors as a mechanism of evolution. But if we also take into account its capacity for self-repair, both at the cellular and embryological level, what field of action remains for Natural Selection for changes in organisms that really involve evolution? [19,20,21].

In 1982, the Welsh astronomer Alfred Hoyle published Evolution from space, in which he theorized about the possibility that the strange ability of the virus integrating itself into the genomes of living beings and remaining in them in the form of "proviruses" could be a mechanism for the acquisition of complex gene sequences, available for eventual use as a response or as a consequence of environmental stimulus or changes [22]. This mechanism would justify the phenomena systematically observed in the fossil record and would explain the profound differences in genetic and morphological existing organization between the large taxa. Currently we know that viral sequences have the ability to integrate into genomes in an ineffective way, simultaneously in a considerable individual numbers, if evidence is found they have a content whose expression makes biological sense, manifested as part of normal vital processes, it would be sufficient indication to seriously consider their character as transporting elements of complex genetic information, and therefore fundamental in the evolution of life. The simultaneous integration in numbers of individuals of sequences of complex biological content (the integration of a complex system within another) would radically change not only the process, the identity of the agent creating new characters, but also the Meaning of this process. The new species suddenly would emerge through a substantial change, as observed in the fossil record and to a considerable number of infected individuals, which would make its inter- fecundity possible. Natural selection would no longer be the force driving of evolution. It would simply be the mechanism of elimination of defective designs during the very long periods of evolutionary ecstasy, during which fit individuals, not the most fit, would reproduce without major problems and with variations with non-essential aspects (in which origin, on the other hand, copy errors of retroviruses cannot be ruled 
out). Let's examine, living beings self-organize (they can only exist) through intense exchanges with their environment, which in turns is organized as a set of dynamic and complexly interrelated ecosystems of living and non-living forms of different levels, among which there are interconnections and interdependence. Finally, the entire Biosphere constitutes a great dynamic and self-regulating ecosystem. Descending to lower levels, the organisms themselves are, open systems formed by units that constitute organs, whose functioning is coordinated with others, each of which is formed by cells, very complex system that includes mechanisms of energy transformation, networks of information and regulation, generation of internal and external structures ..., all these levels have in common the property that the whole is more than the sum of its parts, each of which cannot exist except as a function of existence of others. In this context, even genes can be considered as an individual entity, since their activity, their existence, depends on the coordinated interaction of considerable numbers of regulatory proteins, histones, RNA, even other genes have to act as synchronously. Ultimately, biological processes constitute (and are made of) systems that are integrated into different "quantum" levels, each of which functions as a whole [18]. So, it is worth asking, are the properties of living matter involved in the characteristics of the evolutionary process? It would seem so. The formation of the first eukaryotic cell has been explained by Lynn Margulis and Dorion Sagan in such a convincing way that it can be considered scientifically proven from a morphological as well as a functional point of view. The inclusion of the Prochloron type bacteria, and of the aerobic bacteria similar to Paracoccus or Rhodopseudomonas, among others, are admitted as the origin of chloroplasts and mitochondria. So, if the process that we could qualify as fundamental in the appearance of eukaryotes was produced as a result of the union of several complex systems, would it be possible that this is the main evolutionary mechanism? [23].

\section{2. "Virus" pathological agent or fundamental agent of life}

If viruses share with bacteria the double condition of pathogenic agent (destroyer) and the basic unit of life (builder), the question arises under what conditions does one or the other character manifest? Let's see, coxackieviruses constitute a "family" that is grouped into two types, A and B. Their infection in man causes pathology "only" in $10 \%$ of cases. Some have been well studied experimentally. For example, in mice, CVB3 induces myocarditis, CVB4 pancratitis. In a study in which mice were inoculated with a non-virulent variant of CVB3 (called CVB3 / 0), it was found that a diet deficient in selenium (cellular and extracellular selenoproteins act as antioxidants) produced, ten days after inoculation, the appearance of a single type of extremely virulent CVB3 in different mice [24]. The study of their genome showed that they had undergone six nucleotide changes in the same six positions. Studies of different nucleotide changes in the CVB3 genome have confirmed that there is a limited number of changes associated with virulent character. Although there is a scientific tendency to see what they have been instructed to see (Kuhn's observations), the truth is that the most reasonable interpretation seems to be that of a response to environmental stress $[24,25]$. Another no less significant type of response is that observed by Ter-Grigorovy col, in an experiment in which, in order to observe the response in female mice to autoimmune stimuli, they were crossed for a year with males, reinforcing, after each crossing , the immune response of the: female with male B6 lymphoblasts. Of the 65 resulting mice, 13 developed acute leukemia and in 50 a "chronic disease similar to AIDS developed in which" complete intra and extracellular type $C$ virions appeared with both vertical and horizontal transmission capacity [26]. The meaning of these phenomena seems clear if we add them to the aforementioned activities of viruses: like bacteria, their functional appearance in organisms is altered by environmental aggressions, whether characteristic of the environment or the result of human manipulation, with what would produce its response in the form of a pathogenic agent, its negative aspect would be the consequence of some factor that breaks the natural balance of its activity. Likewise, if bacteria have been shown as a fundamental basis not only in the origin of living beings, but in the functioning of life, is it possible to find a function similar to the bacterial one in the double condition of viruses? In another sense, are viruses a "special case" among the different possible life manifestations, or are they a fundamental element of it? Let's see what the data suggests:

1. According to studies results in marine waters, viruses are the most diverse and numerous creatures on earth. Only in marine waters they are 5 to 25 times more abundant than bacteria, it can be assumed that the population of soils will be, at least, proportional, their ecological role can be considered as the basis of marine ecosystems $[27,28,29,30]$. Some of these functions are also being verified in terrestrial ecosystems [31]. Up to $80 \%$ of the genetic sequences of marine and terrestrial viruses are not known in any animal or plant organism [32,33]. The amount, not only of "genes but of fundamental proteins in eukaryotic organisms (especially multicellular) acquired from viruses would be endless $[34,35,36,37,38,39]$, although on occasions, the discoverers themselves, led by the Darwinian interpretation, consider them to appear mysteriously (at random) in eukaryotes and acquired by viruses [40] those who accuse them of being hijackers "," flavors "or" imitators " [36] without taking into account that viruses in the free state are absolutely inert and that it is the cell that uses and activates the components of viruses [41]. Therefore, it is appropriate to clarify that the viruses "do not mutate to evade host defenses", mutations occur during integration processes in cellular DNA because viral reverse transcriptase does not correct "copy errors". According to the report of the United Nations Environment Program (PNUMA, 2000), the estimated minimum number of both bacteria and virus, for now unknown, 
is at least one hundred times higher. It seems clear that its pathogenic appearance is extremely minor. If they were "our competitors" of course we would have little chance of "beating them."

2.There is a considerable amount of complex processes and specific molecules of eukaryotic cell that do not come from bacteria and are, necessarily, of viral origin. Many related to genetic information [42,43], such as mRNAs, linear chromosomes and the separation of translational transcription [44], polymerases [45], introns [46], telomeres and telomerases [47] or with processes related to cell division such as meiosis [48] or of mitochondrial replication and transcription proteins [49] but also many molecules, especially proteins and enzymes, not existing in prokaryotes. Likewise, the appearance of the mammalian placenta has been shown to have elements of retroviral origin involved in different aspects of its functioning [50,51,52]. According to the results of The Human Genome Sequencing Consortium, 2001 , the sequencing of the protein coding fraction, which constitutes $15 \%$ of the total human genome (in addition to 233 genes identified as of bacterial origin) up to $50 \%$ of its sequences are formed by mobile elements, above $10 \%$ are endogenous viruses and "Much of the remaining DNA must also be derived from old copies of transposable elements that have diverged too much to be recognizable as such [53]. As for the remaining 98.5\%, the "non-coding" or "junk" fraction thanks to the contribution of Richard Dawkins [54], it has been possible to verify that it is not only one more component of the genomes (that there is no garbage), but it is the fundamental component in the explanation of variability, biological complexity [55], in the understanding of evolution [56]. All this leads to the inevitable conclusion that animal and plant genomes are made up of a sum of bacterial and viral genomes.

\section{Discussion}

The abrupt morphological remodeling revealed by the fossil record and the acquisitions of new morphologies or capacities can only be explained through the prism of the integrated performance of these systems with specific biological content. The evolution (the change of organization) therefore, is produced by Integration of Complex Systems [57], which are organized into systems of greater complexity. That is, a phenomenon of cooperation between different units, a characteristic that can be applied to all biological phenomena, from the cell to tissues and organs, from individuals to ecosystems, from cells to tissues. The basic units would be bacteria that have all the fundamental processes and mechanisms of cellular life, whose components seem to have been conserved with very few changes throughout the evolutionary process. Viruses, through their evolutionary mechanism of chromosomal integration, would be those that either individually or through combinations between them, would introduce the new sequences responsible for the embryonic control of the appearance of new tissues and organs, as well as the regulation of their functioning. The responsiveness of bacteria and viruses to environmental stimuli would justify the inevitably rapid and extensive changes that the fossil record shows forced by the complex Internet [58]. Interrelation of some tissues with others and with the whole body. Its infective character would make these changes possible simultaneously in a considerable number of individuals. On the other hand, this infective character could be involved in mass and selective extinctions. Many coincide with a period of environmental disturbances, which would be part of the mechanism of the evolutionary process. Recalling Kuhn's arguments, the consequences of this new perspective are not just a change in the theoretical model. Its bases and the mechanism of control of vital processes necessarily lead to a new way of interpreting them and, therefore, to a new perception and attitude towards nature [59]. If the social (cultural) model largely determines the way of seeing and relating to the world, it seems clear that the substitution of the paradigm based on competition and irresponsible chance for one of maturation as a whole essential unity and cooperation but especially prudence and respect in the face of what we do not know or control, must be accompanied or preceded by a substantial change in the foundations and social and cultural values.

\section{Conclusion}

The cosmos refers to the image of an order, this order leads us, in turn, towards the existence of a cause and an external end. Nature has its own rules in which everything, each atom. Each fragment, each speck of dust, each virus, is involved in the maintenance and regulation of on life on Earth and has a great capacity to recover from the worst environmental catastrophes. The permanent attack on the fundamental elements is this regulation, the attack on the "network of life". It can have consequences that, unfortunately, we can only see when Nature regains its balance. Following the steps of all the above, we can apprehend the universe as a message expressed in a secret code, which we have just begun to decipher. This is how the cosmic code breaks down: first matter, then energy, and finally information. If we accept the idea that the universe is a secret message, who composed this message? If the enigma of that cosmic code has been imposed on us by its author, does not our task of deciphering it form a kind of plot, an increasingly clear mirror in which the author of the message renews the knowledge he has of himself? "The universe is a machine that creates gods ..." (Henri Bergson). 


\section{Compliance with ethical standards}

\section{Acknowledgments}

CMA is Doctoral Fellow from CONICET, CSS and MJC are members of the Research Career from CONICET. The authors that the research was conducted in the absence of any commercial or financial relationships that could be construed as a potential of interest.

\section{Disclosure of conflict of interest}

All of the authors declare there are no conflicts of interest in connection with this paper, and the material described is not under publication or consideration for publication elsewhere.

\section{References}

[1] Argüelles J. El factor maya, un camino más allá de la tecnología. Edit. Brujas. Córdoba. Argentina. 2005.

[2] Guitton J, Bogdanov G, Bogdanov I. Dios y la Ciencia. Emice Editores. S.A. Buenos Aires. Argentina. 1992.

[3] Prigogine I, Stengers I. La nueva alianza Metamorfosis de la ciencia. Alianza Editorial, S. A., Madrid. España. 1983.

[4] Gavin AC, Krause MR, Grandi P, Marzioch M, Bauer A, Schultz J, et al. Functional organization of the yeast proteome by systematic analysis of protein complexes. Nature. 2002; 415:141-147.

[5] Ho Y, Gruhler A, Heilbut A, Bader GD, Moore L, Adams SL, et al. Systematic identification of protein complexes in Saccharomyces cerevisiae by mass spectometry. Nature. 2002; 415: 180-183.

[6] Oliva AM. Lo que tu luz dice. Un viaje desde la tecnología hacia la consciencia. Editorial Sirio. España. 2014.

[7] Castañeda MA, Sepulveda C, Carlucci MJ. In time of global planetary challenges: Metanoia. Austin Anthropol. 2020; 4(1): 10-16.

[8] Bohm D. La Plénitude de l’Univers, Le Rocher. 1988.

[9] Scott B. Heinz von Foerster-An appreciation. Cybernetics and human knowing. 2003; 10(3): 137-149.

[10] Von Foerster H, Poerksen B. Understanding systems. Dordrecht: Kluwer. 2002.

[11] d’Espagnat B. A la recherche du réel. Gaurthier-Villars. 1979.

[12] Schrodinger E. Quést-ce que la vie? Bourgois. 1986.

[13] Harrison RG. Embriology and its relations. Science. 1937; 85: 369-374.

[14] Weiss P. Principles of development. Holt, New York. 1939.

[15] Child CM. Patterns and problems of development. Univ. of Chicago Press. Chicago. 1941.

[16] Beatty J.Opportunities for genetics in the atomic age. Hellon Symposium, Institutional and Disciplinary contexts of the life science. M.T.I Cambridge, MA. 1994.

[17] Mitman G, Fausto-Sterling A. Whatever happened to planaria? CM Child and the physiology of inheritance. In The right tool for the right job: At work in twentieth-century life science. Ed. AE Clarke \& JH Fujimura. Princenton Univ, Pricenton. 1989.

[18] Sandin M. Pensando la evolución, pensando la vida. Cauac Editorial Nativa. España. 2010.

[19] Gilbert SF, Opitz JM, Raff RA. Resynthesizing evolutionary and developmental biology. Developmental Biology. 1996; 173: 357-372.

[20] Prevosti P. Darwinismo y mendelismo. En el centenario de Mendel: La genética ayer y hoy. Ed. Alhambra, Madrid. 1984.

[21] Scolaro LA, Roldan JS, Theaux C, Damonte EB, Carlucci MJ. Experimental aspects suggesting a "fluxus" of information in the virions of herpes simplex virus populations. Frontiers of Microbiology, Virology. 2017; 22(8): 2625.

[22] Hoyle A. Evolution from space. University College Cardiff Press. 1982. 
[23] Margulis L, Sagan D. El origen de la célula eucariota. Mundo científico. 1985; 5-46.

[24] Gauntt C, Tracy S. Deficient diet evokes nasty heart virus. Nature Medicine.1995; 1(5): 405-406.

[25] Theaux C, Scolaro L, Carlucci MJ. 2019. Viral musicality in harmony with nature. Biology and Medicine. Biol Med (Aligarh). 2019; 11(2): 461.

[26] Ter-Grigorov SV, Krifuks O, Liubashevsky E, Nyska A, Trainin Z, Toder V. A new transmissible AIDS-like disease in mice induced by alloimmune stimuli. Nature Medicine. 1997; 3(1): 37-41.

[27] Carluci MJ, Damonte EB, Scolaro LA. Virus driven evolution: a probable explanation for "Similia Similibus Curantur" philosophy. Infect Genet Evol. 2011;11(5): 798-802.

[28] Carlucci MJ, Mateu CG, Artuso MC, Scolaro LA. Polysaccharides from Red Algae: Genesis of a Renaissance. Editorial: InTech. Croacia. The Complex World of Polysaccharides, edited by Desiree Nedra Karunaratne 2012; 535-554.

[29] Fuhrman JA. Marine viruses and their biogeochemical and ecological effects. Nature. 1999; 399: 541-548.

[30] Suttle CA. Viruses in the sea. Nature. 2005; 437: 356-361.

[31] Williamson KE, Wommack KE, Radosevich M. Sampling Natural Viral Communities from Soil for CultureIndependent Analyses. Applied and Environmental Microbiology. 2003; 69(11): 6628-6633.

[32] Villarreal LP. Viruses and the Evolution of Life. ASM Press, Washington. 2004.

[33] Artuso MC, Roldán JS, Scolaro LA, Carlucci MJ. Viruses: as mediators in "elan vital" of the "creative" evolution. Infect Genet Evol. 2016; 46: 78-84.

[34] Adams JM, Cory S. The Bcl-2 protein family: arbiters of cell survival. Science 1998; 28: 1322-1326.

[35] Barry M, McFadden G. Apoptosis regulators from DNA viruses. Current Opinion Immunology.1998;10: 422-430.

[36] Markine-Goriaynoff N, Gillet L, Van Etten JL, Korres H, Verma N, Vanderplasschen A. Glycosiltransferases encoded by viruses. Journal of General Virology. 2004; 85: 2741-2754.

[37] Gabus C, Auxilien S, Pechoux C, Dormont D, Swietnicki W, Morillas M, Surewicz W, Nandi P, Darlix JL. The prion protein has DNA strand transfer properties similar to retroviral nucleocapsid protein. Journal of Molecular Biology. 2001; 307(4): 1011-1021.

[38] Medtrand P, Mag DL. Human-specific integrations of the HERV-K Endogenous Retrovirus Family. Journal of Virology. 1998; 72(12): 9782-9787.

[39] Jamain S, Girondot M, Leroy P, Clergue M, Quach H, Fellous M, Bourgeron T. Transduction of the human gene FAM8A1 by endogenous retrovirus during primate evolution. A Genomics. 2001; 78: 38-45.

[40] Hughes AL, Friedman R. Genome-Wide Survey for Genes Horizontaly Transferred from Cellular Organisms to Baculoviruses. Molecular Biology and Evolution. 2003; 20(6): 979-987.

[41] Cohen J. HIV gets by with a lot of help from human host. Science. 2008; 319(5860):143-144.

[42] Sandin M. Las “sorpresas” del genoma. Boletin de la Real Sociedad Española de historia Natural (sección Biología). 2001; 96(3-4): 345-352.

[43] Sandin M. Hacia una nueva Biología. Arbor. 2002; 677: 167-218.

[44] Bell PJ. Viral eukaryogenesis: was the ancestor of the nucleus a complex DNA virus? Journal of Molecular Evolution. 2001; 53(3): 251-256.

[45] Villarreal LP. De Filippis VR. A Hypothesis for DNA Viruses as the Origin of Eukaryoic Replication Proteins. Journal of Virology. 2000; 76(15): 7079-7084.

[46] Fedorov A, Roy S, Fedorova L, Gilbert W. Mistery of intron gain. Genetics Research. 2003; 13: 2236-2241.

[47] Schawalder J, Paric E, Neff NF. Telomere and ribosomal DNA repeats are chromosomal target of the bloom syndrome DNA helicase. BioMed Central Cell Biology. 2003; 4: 11.

[48] Livingstone Bell PJ. Sex and the eukaryotic cell cycle is consistent with a viral ancestry for the eukaryotic nucleus. Journal of Theoretical Biology. 2006; 243(1): 54-63.

[49] Shutt TE, Gray MW. Bacteriophage origins of mitochondrial replication and transcription proteins. Trends in Genetics. 2006; 22(2): 92-95. 
[50] Hall SG. Genetic imprinting: Review and relevance to human diseases. American Journal of Human Genetics. 1990; 46: 857-873.

[51] Neumann B, Kubicka P, Barlow DP. Characteristics of imprinted genes. Nature Genetics. 1995; 9: 12-13.

[52] Lyden TW, Johnson PM, Mwenda JM, Rote NS. Expresion of endogenous HIV-1 crossreactive antigens within normal extravillous trophoblast cells. Joumal of Reproductive Inmunoloy.1995; 28: 3.

[53] The Genome sequencing consortium. Initial sequencing and analysis of the human genome. Nature. 2001; 409: 860-921.

[54] Von Sternberg R. On the Roles of Repetitive DNA Elements in the context of a Unified Genomic-Epigenetic system. Annals of the New York Academy of Sciences. 2002; 981:154-188.

[55] Mattick JS. Challenging he Dogma: the hidden 1ayer of non-protein-coding RNAs in complex organisms. BioEssays. 2003; 25: 930-935.

[56] Makalowsky W. Not junk after all. Science. 2003; 300: 1246-1247.

[57] Sandin M. Teoría Sintética: Crisis y revolución. Arbor. 1997; 623-624: 269-303.

[58] Goldenfeld N, Woese C. Biology's next revolution. Nature. 2007; 445: 369.

[59] Kuhn TS. The structure of scientific revolutions. University of Chicago Press. 1962. 